Supporting Information for

\title{
One-dimensional lead-free halide with near-unity greenish-yellow light emission
}

Sai Li, ${ }^{\dagger}$ Jun $\mathrm{Xu},{ }^{\dagger}$ Zhigang Li, ${ }^{\dagger}$ Zhichao Zeng, ${ }^{\dagger}$ Wei Li, ${ }^{\dagger}$ Minghuan Cui, ${ }^{\ddagger}$ ChaoChao Qin ${ }^{\ddagger}$ and Yaping $\mathrm{Du}^{*}+{ }^{+}$

${ }^{+}$Tianjin Key Lab for Rare Earth Materials and Applications, Center for Rare Earth and Inorganic Functional Materials, School of Materials Science and Engineering \& National Institute for Advanced Materials, Nankai University, Tianjin 300350, P.R. China.

‡Henan Key Laboratory of Infrared Materials \& Spectrum Measures and Applications, Henan Normal University, Xinxiang 453007, P. R. China.

E-mail: ypdu@nankai.edu.cn 
Table S1. Comparison of photoluminescence quantum efficiency (PLQY) values of the greenish-yellow luminescence of halide perovskites and relevant materials.

\begin{tabular}{cccccc}
\hline Materials & $\begin{array}{c}\text { Electronic } \\
\text { dimension }\end{array}$ & $\begin{array}{c}\text { Emission peak } \\
{[\mathrm{nm}]}\end{array}$ & $\begin{array}{c}\text { PLQY } \\
{[\%]}\end{array}$ & $\begin{array}{c}\text { Pros and } \\
\text { cons }\end{array}$ & Ref. \\
\hline$(\mathrm{KC})_{2} \mathrm{MnCl}_{4}$ & DD & 518 & 7.79 & Weak PL & 1 \\
$\left(\mathrm{C}_{9} \mathrm{NH}_{20}\right)_{6} \mathrm{~Pb}_{3} \mathrm{Br}_{12}$ & OD & 522 & 12 & toxic & 2 \\
{$[\mathrm{Bzmim}]_{3} \mathrm{SbCl}_{6}$} & OD & 525 & 87.5 & toxic & 3 \\
$\mathrm{C}_{3} \mathrm{Bi}_{2} \mathrm{I}_{9}$ & OD & 545 & 0.018 & Weak PL & 4 \\
{$\left[\mathrm{KC}_{2}\right]_{2}\left[\mathrm{Cu}_{4} \mathrm{I}_{6}\right]$} & 1D & 540 & 97.8 & stable, & this \\
\hline
\end{tabular}
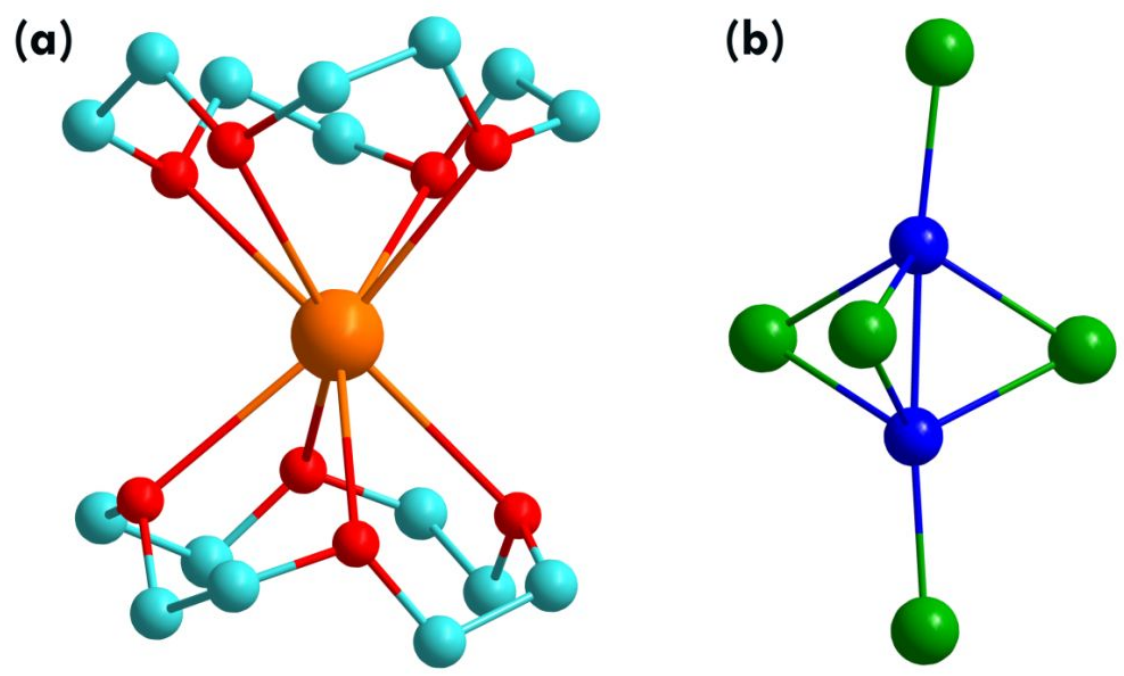

Figure S1. Crystal structure of [(12-crown- 4$\left.)_{2} \mathrm{~K}\right]^{+}$ions and two adjacent inorganic $\mathrm{CuI}_{4}$ units. (orange: potassium atoms; green: iodine atoms; blue: copper atoms; red: oxygen; aqua: carbon atoms; hydrogen atoms were hidden for clarity).

(a)
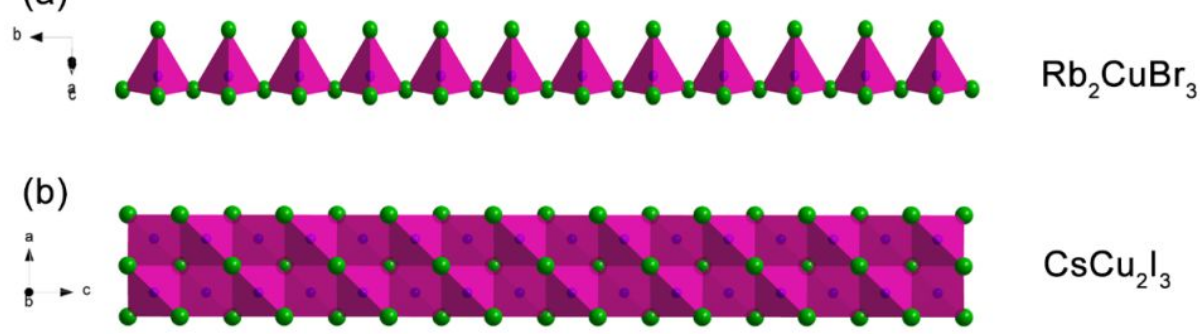

(c)

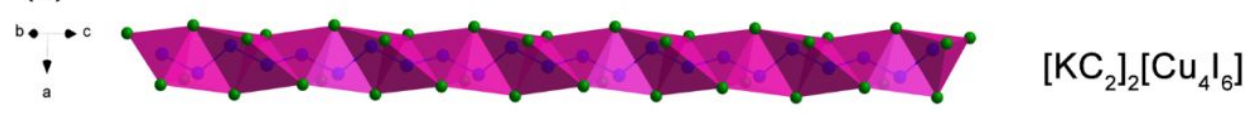

Figure S2. individual copper iodide chain in the different 1D copper(I)-based halides. The green spheres are halide atoms (bromine in $\mathrm{Rb}_{2} \mathrm{CuBr}_{3}$, iodine in $\mathrm{CsCu}_{2} \mathrm{I}_{3}$ and $\left[\mathrm{KC}_{2}\right]_{2}\left[\mathrm{Cu}_{4} \mathrm{I}_{6}\right]$ ), and the blue spheres are cooper atoms. 


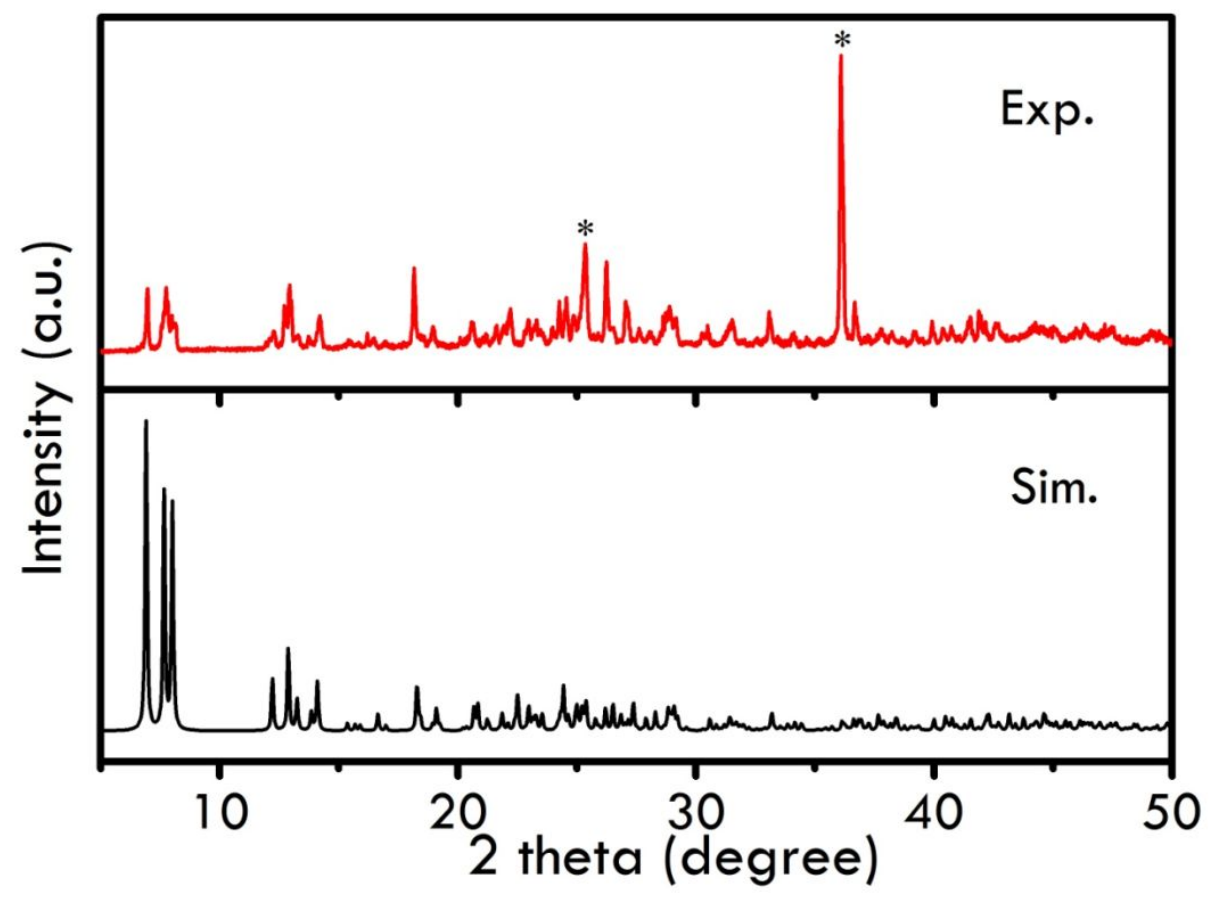

Figure S3. PXRD pattern of $\left[\mathrm{KC}_{2}\right]_{2}\left[\mathrm{Cu}_{4} \mathrm{I}_{6}\right]$ as well as the simulated results. The marked peaks are attributed to potassium iodide.

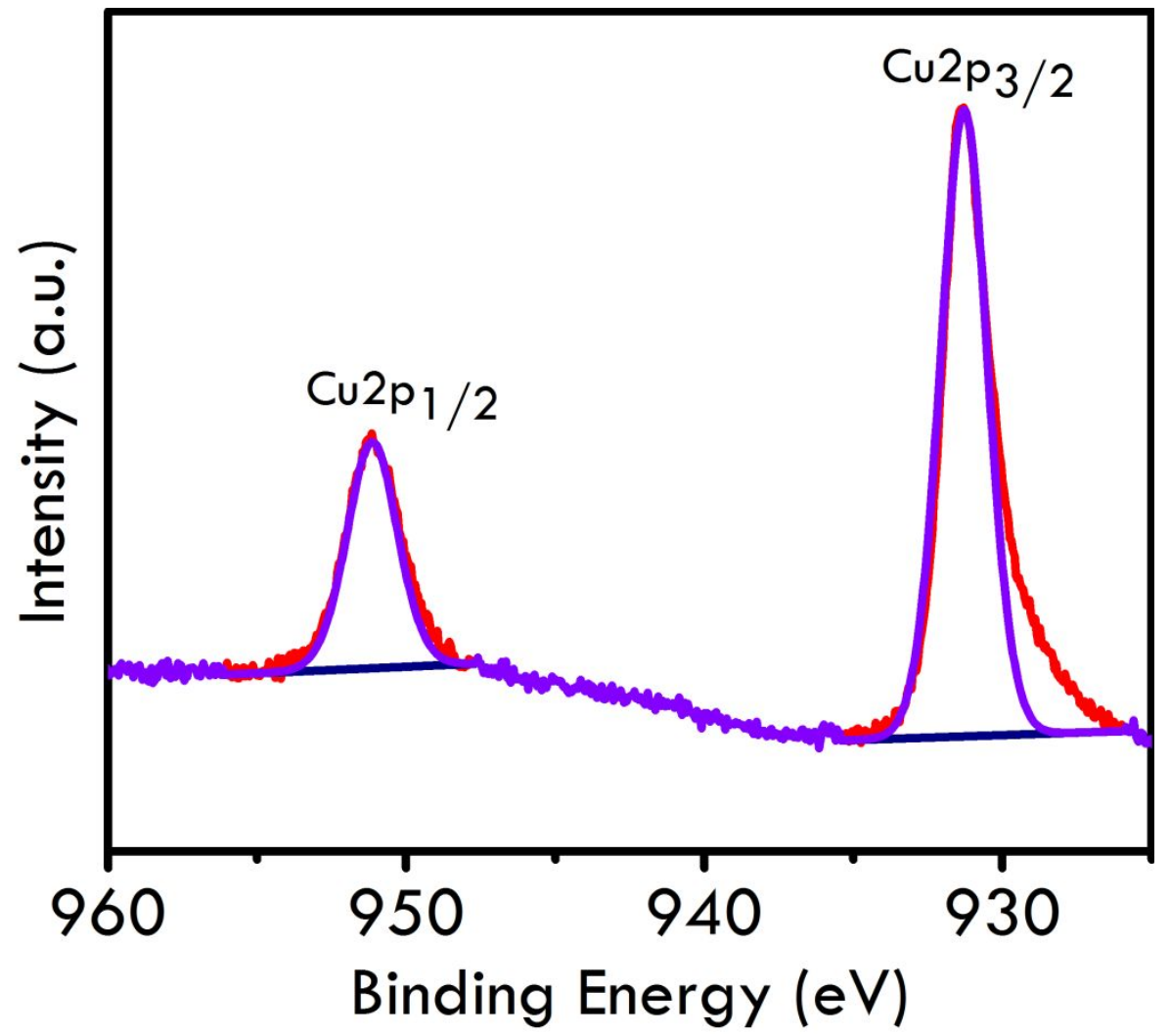

Figure S4. XPS analysis of $\left[(12 \text {-crown- } 4)_{2} \mathrm{~K}_{2}\left[\mathrm{Cu}_{4} \mathrm{I}_{6}\right]\right.$. 


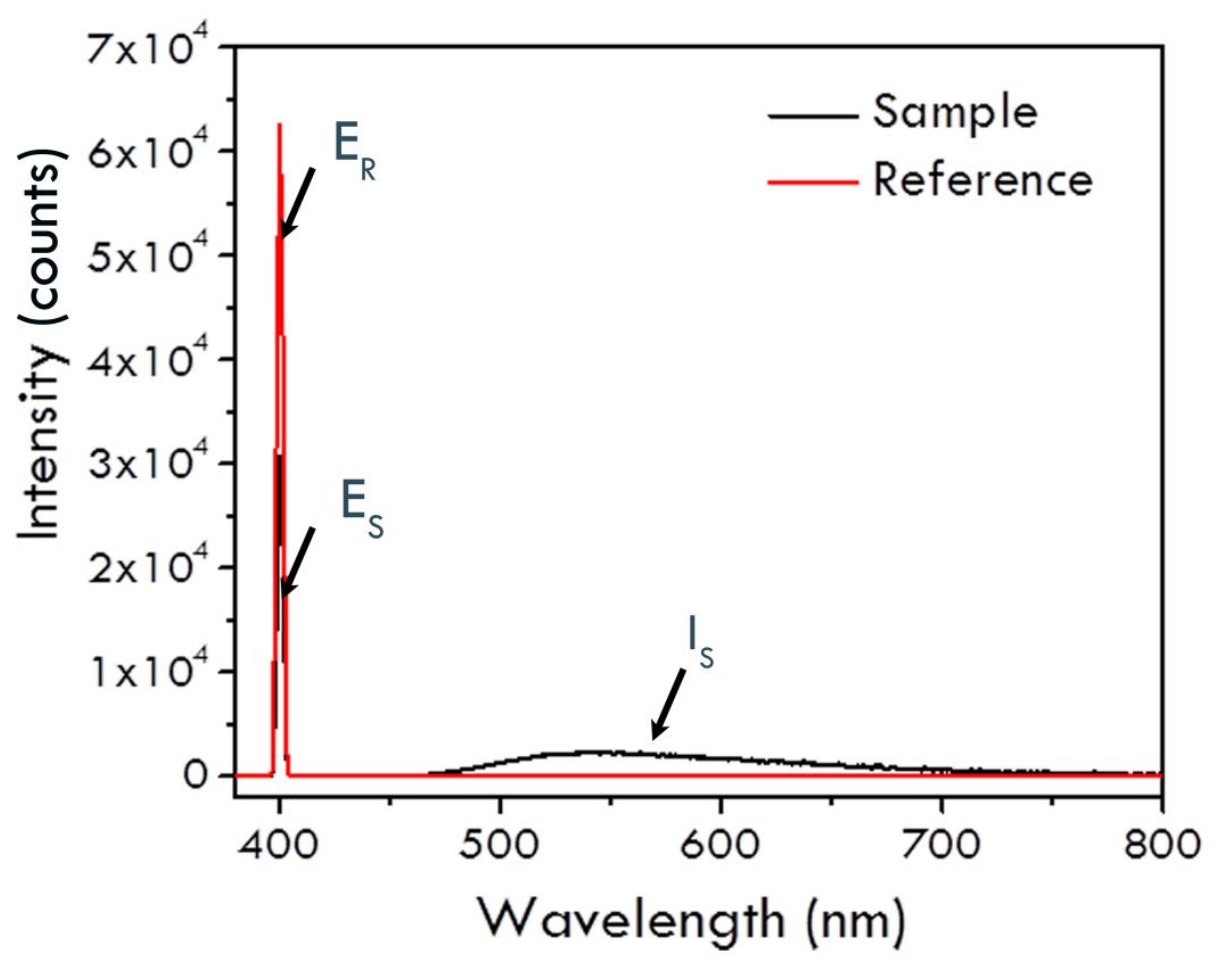

Figure S5. Excitation line of reference $(400 \mathrm{~nm})$ and emission spectrum of bulk crystals collected by an integrating sphere system. The PLQY was calculated based on the equation: $\eta_{Q E}=I_{S} /\left(E_{R}-E_{S}\right)$, which $I_{S}$ represents the luminescence emission spectrum of the sample, $E_{R}$ is the spectrum of the excitation light from the empty integrated sphere (without the sample), and $\mathrm{E}_{\mathrm{S}}$ is the excitation spectrum for exciting the sample. Control samples, $\mathrm{BaMgAl}_{10} \mathrm{O}_{17}: \mathrm{Eu}^{2+}$ and $\left[\mathrm{K}(18 \text {-crown-6) }]_{2} \mathrm{SbCl}_{5}\right.$, were measured using this method to give PLQE of $93 \%$ and $54 \%$, respectively, which are close to the literature reported values. ${ }^{5}$

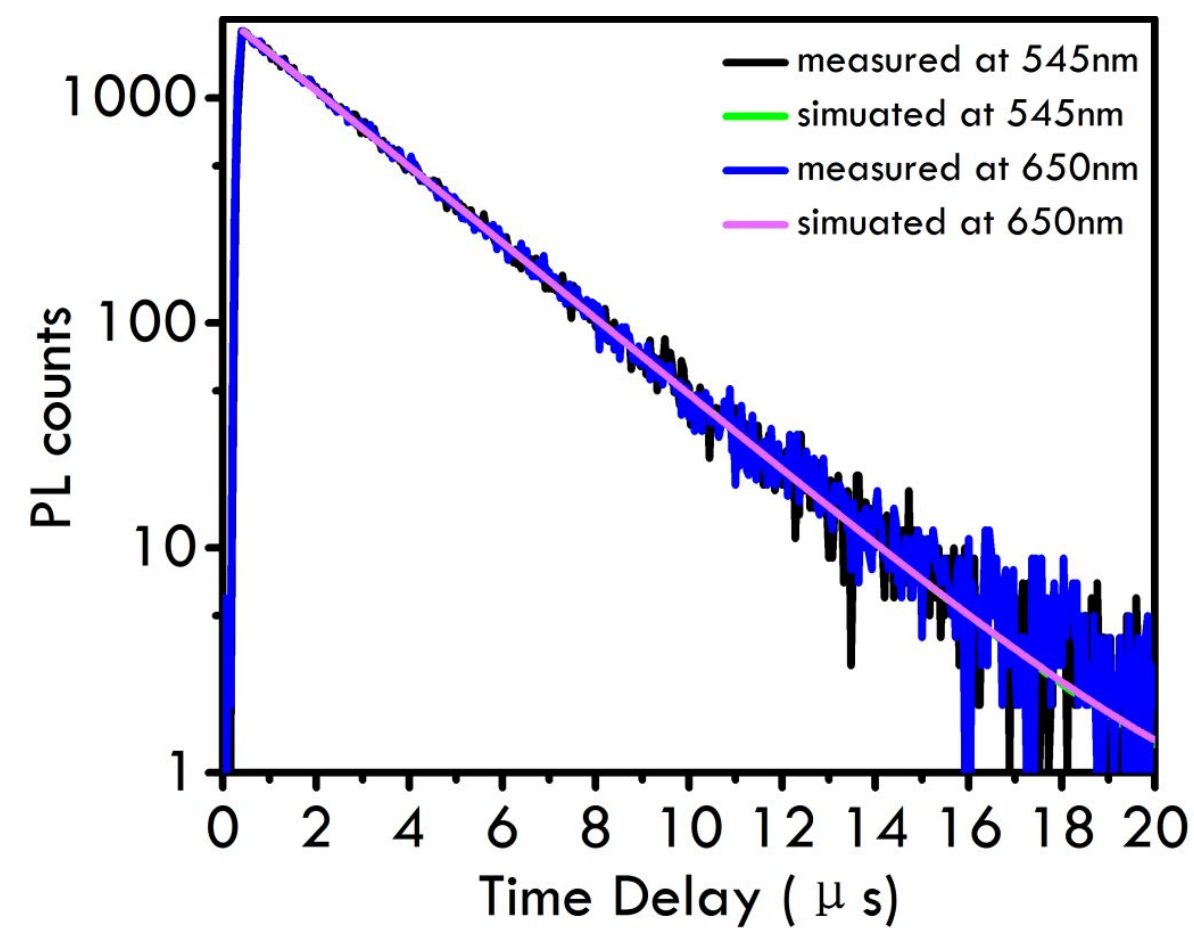

Figure S6. Time-resolved photoluminescence decay of $\left[\mathrm{KC}_{2}\right]_{2}\left[\mathrm{Cu}_{4} \mathrm{I}_{6}\right]$ monitored at $545 \mathrm{~nm}$ and $650 \mathrm{~nm}$. 


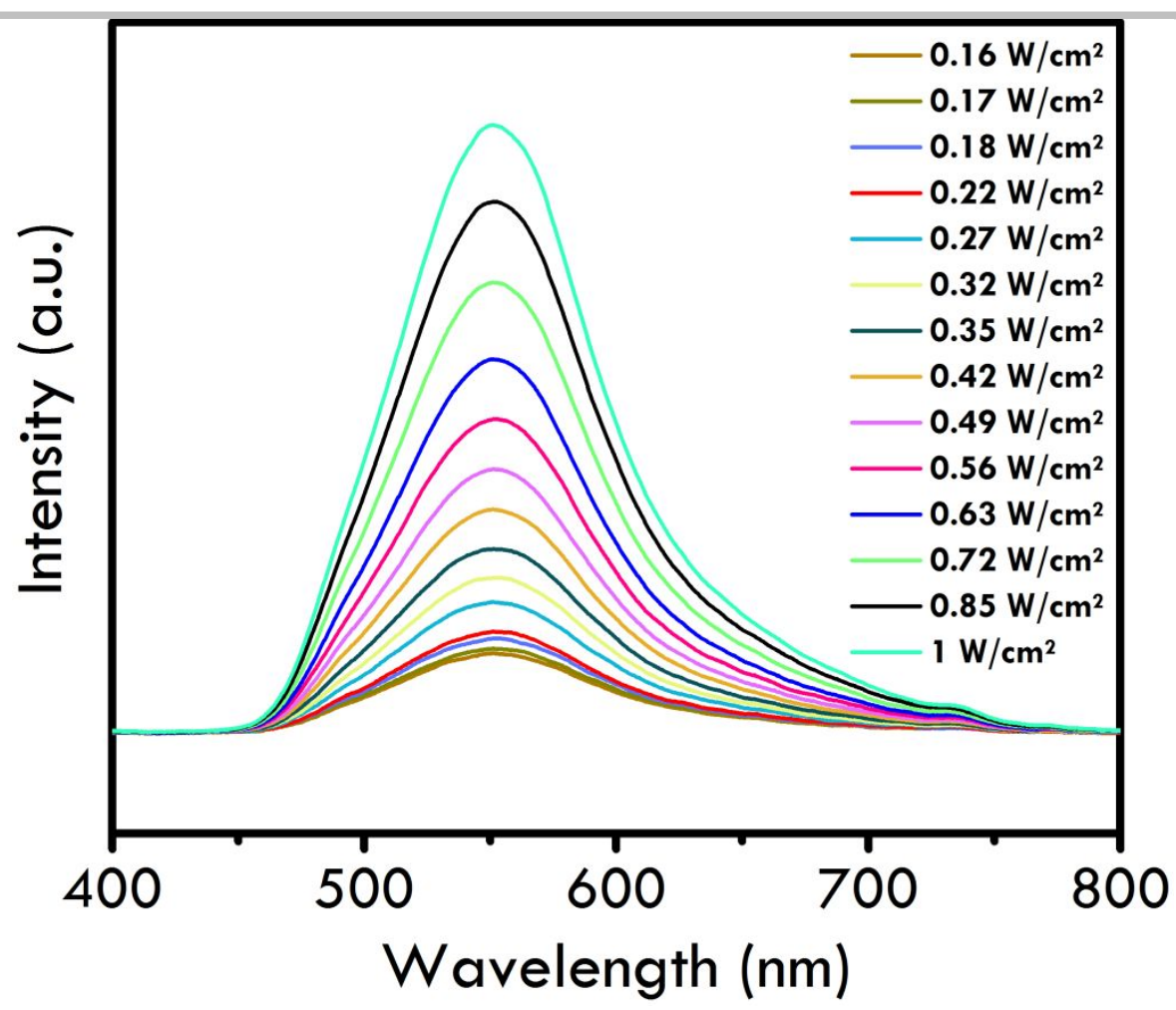

Figure S7. Emission spectra at different excitation powers.
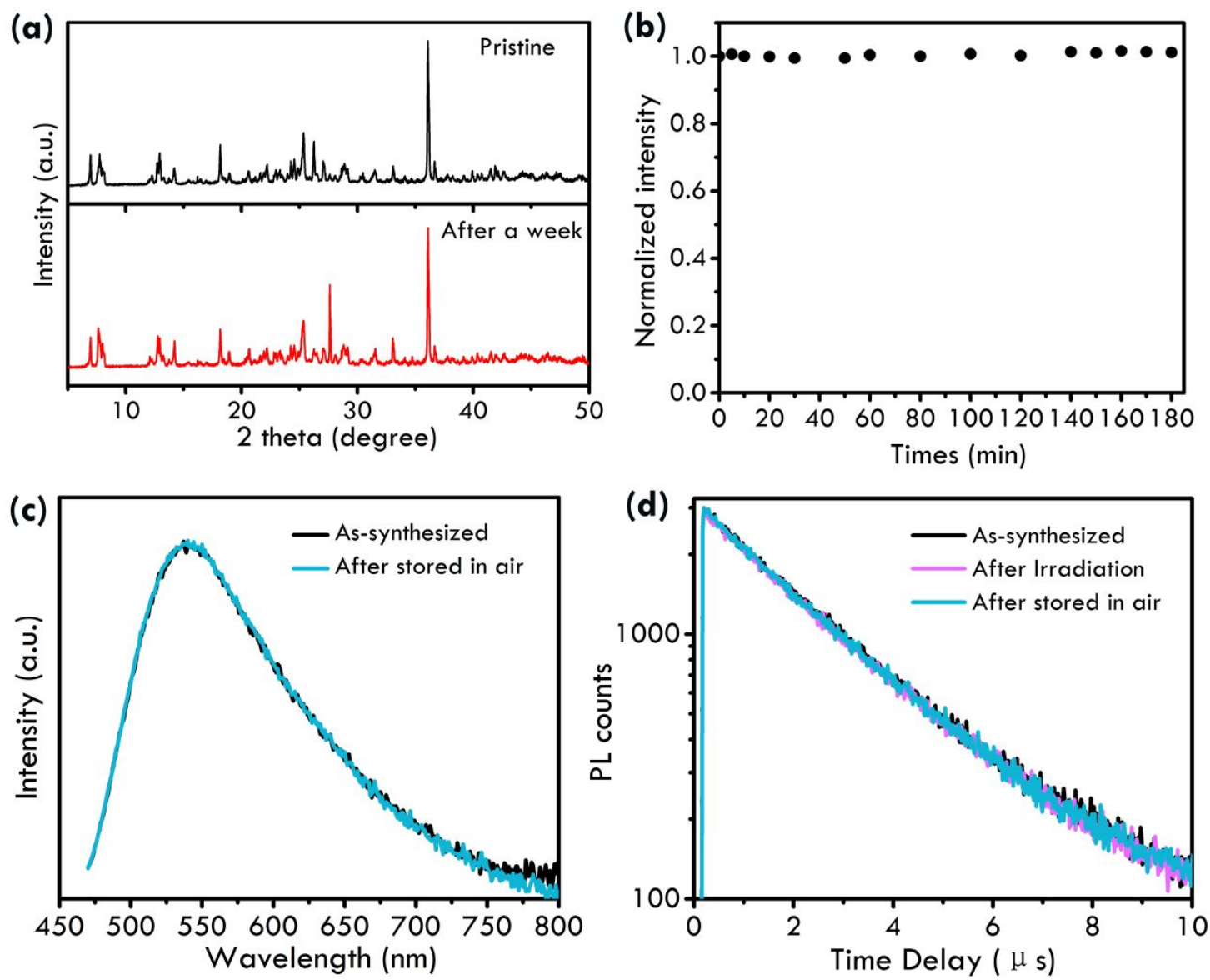

Figure S8. (a) The structural stability of $\left[\mathrm{KC}_{2}\right]_{2}\left[\mathrm{Cu}_{4} \mathrm{I}_{6}\right]$. (b) The photostability of $\left[\mathrm{KC}_{2}\right]_{2}\left[\mathrm{Cu}_{4} \mathrm{I}_{6}\right]$ of different irradiation time with a 350W xenon lamp. (c) Emission spectra of pristine sample and sample stored in air for a week. (d) PL lifetime of pristine sample, sample radiated for 3 hours and sample stored in air for a week sample monitored at $545 \mathrm{~nm}$. 


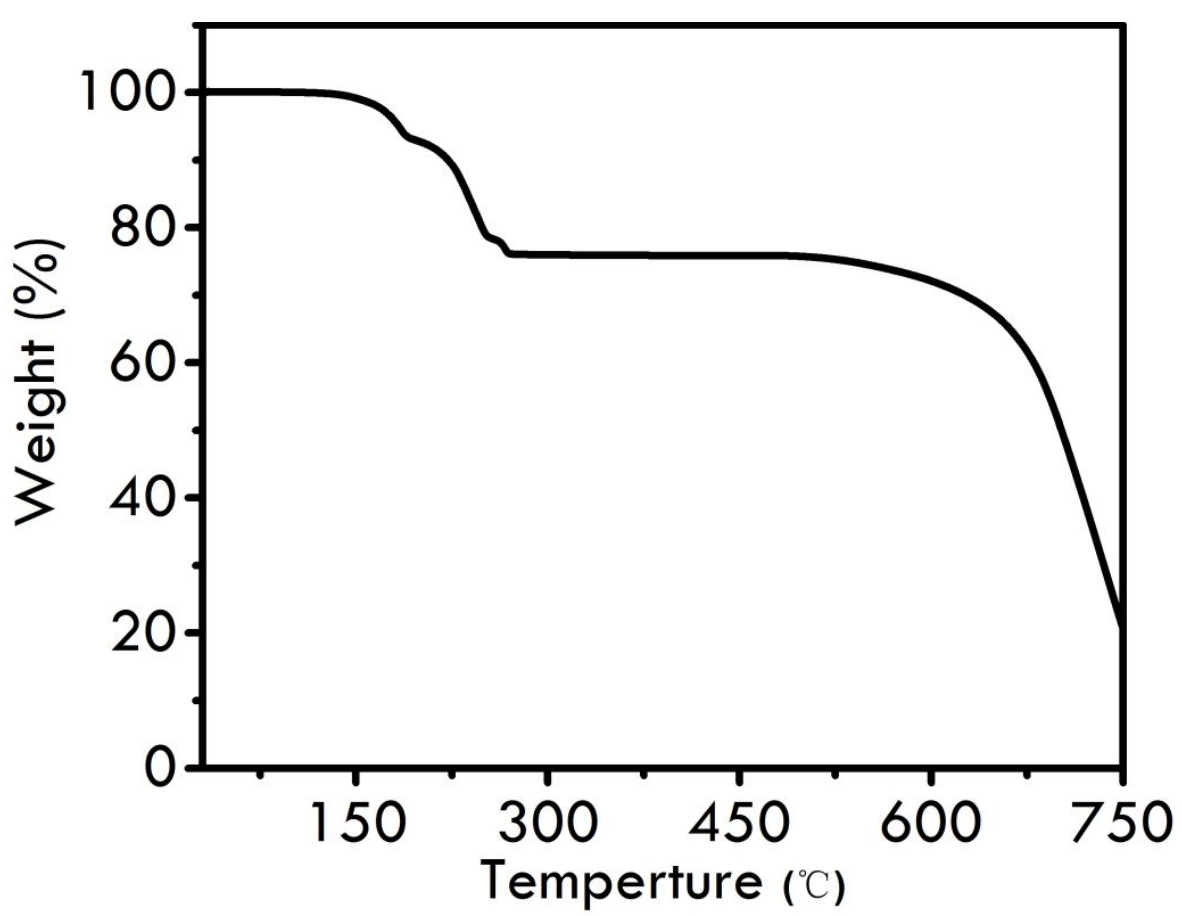

Figure S9. Thermogravimetric analysis (TGA) of $\left[\mathrm{KC}_{2}\right]_{2}\left[\mathrm{Cu}_{4} \mathrm{I}_{6}\right]$. The sample begins to decompose at about $140{ }^{\circ} \mathrm{C}$.

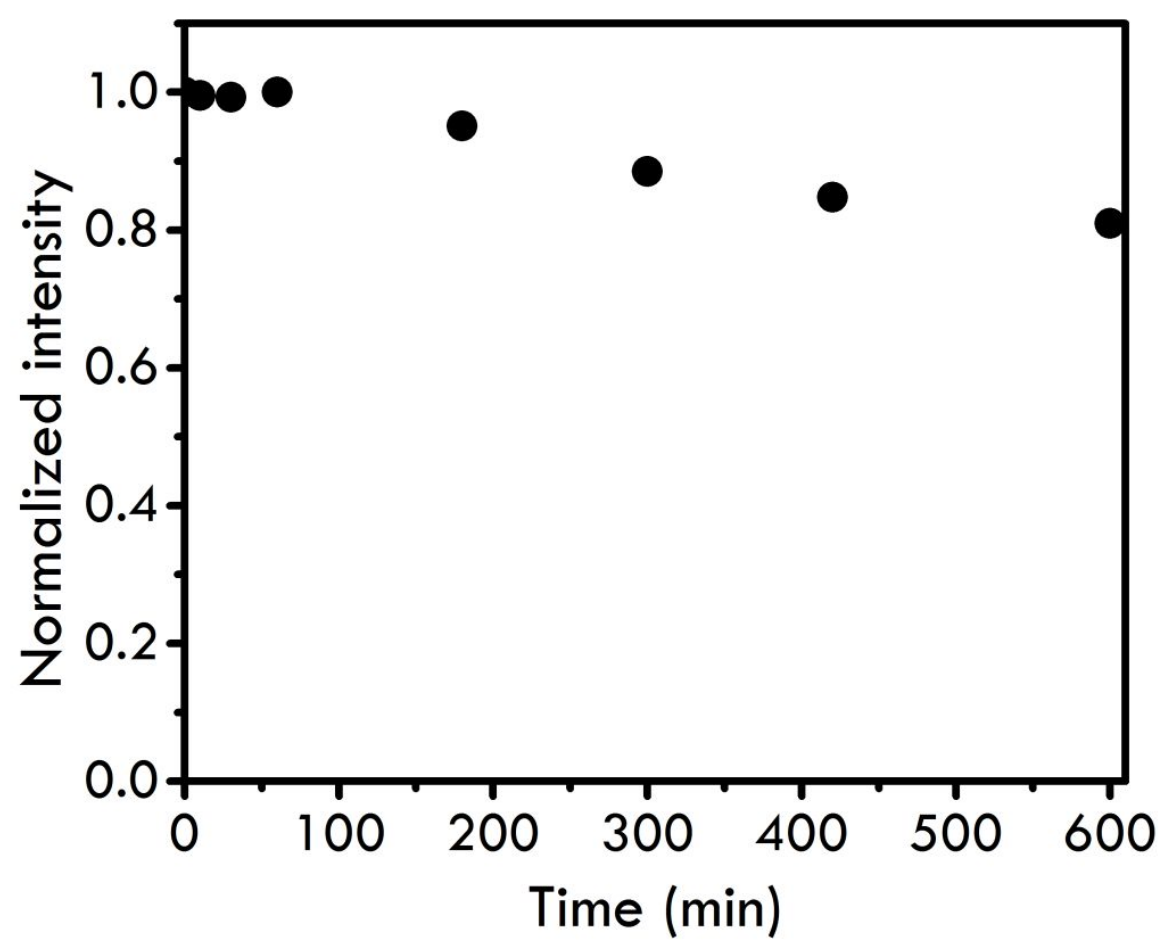

Figure S10. PL spectra of the WLED measured at different working time. 


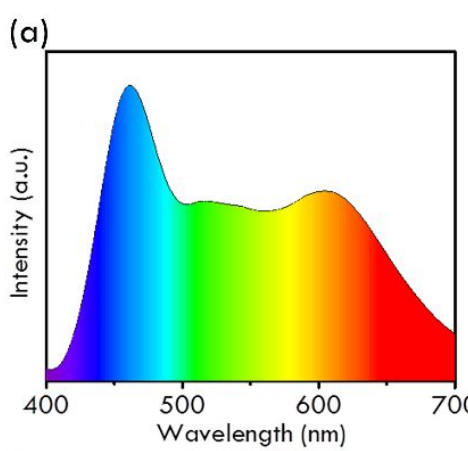

(c)

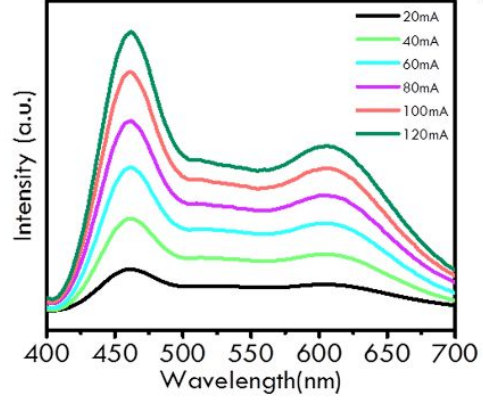

(b)

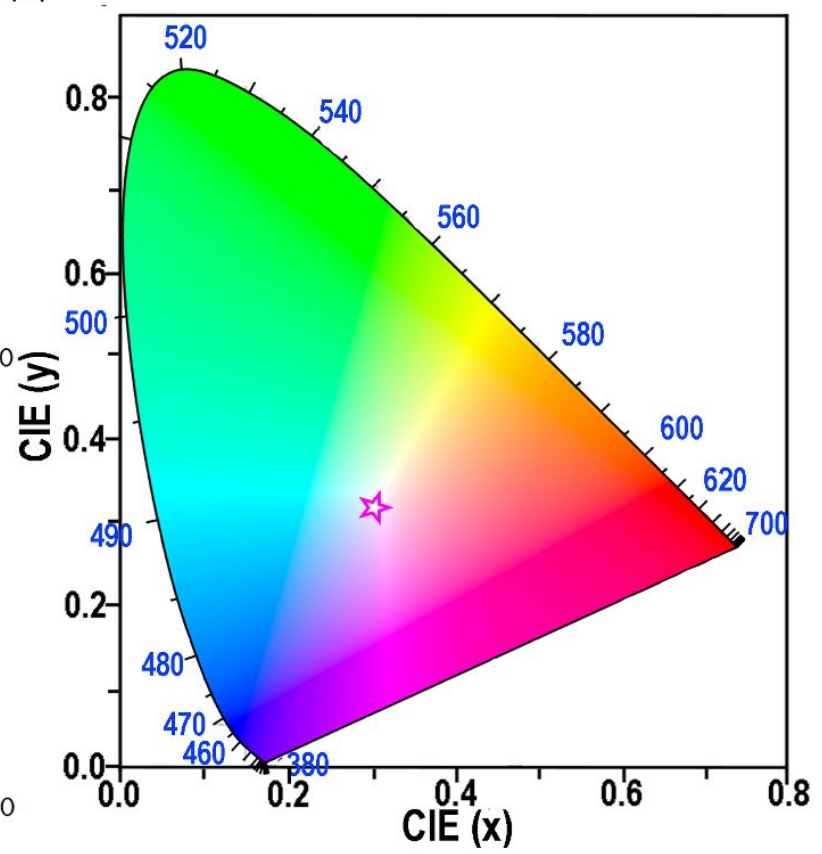

Figure S11. (a) Luminescence spectra from $\left[\mathrm{KC}_{2}\right]_{2}\left[\mathrm{Cu}_{4} \mathrm{I}_{6}\right]$-based white light-emitting diodes (LEDs) excited with a $450 \mathrm{~nm}$ blue chip. (b) CIE coordinates corresponding to white-LED device (pink star). (c) The emission spectra of white-LED device at different driving currents.

\section{References}

(1) Zhao, J.; Zhang, T.; Dong, X. Y.; Sun, M. E.; Zhang, C.; Li, X.; Zhao, Y. S.; Zang, S. Q. Circularly Polarized Luminescence from Achiral Single Crystals of Hybrid Manganese Halides. J. Am. Chem. Soc. 2019, 141, 15755-15760.

(2) Yuan, Z.; Zhou, C.; Tian, Y.; Shu, Y.; Messier, J.; Wang, J. C.; van de Burgt, L. J.; Kountouriotis, K.; Xin, Y.; Holt, E.; Schanze, K.; Clark, R.; Siegrist, T.; Ma, B. One-Dimensional Organic Lead Halide Perovskites with Efficient Bluish White-Light Emission. Nat. Commun. 2017, 8, 14051.

(3) Wang, Z.; Zhang, Z.; Tao, L.; Shen, N.; Hu, B.; Gong, L.; Li, J.; Chen, X.; Huang, X. Hybrid Chloroantimonates(III): Thermally Induced TripleMode Reversible Luminescent Switching and Laser-Printable Rewritable Luminescent Paper. Angew. Chem. Int. Ed. 2019, 58, $9974-9978$.

(4) Leng, M.; Yang, Y.; Zeng, K.; Chen, Z.; Tan, Z.; Li, S.; Li, J.; Xu, B.; Li, D.; Hautzinger, M. P.; Fu, Y.; Zhai, T.; Xu, L.; Niu, G.; Jin, S.; Tang, J. All-Inorganic Bismuth-Based Perovskite Quantum Dots with Bright Blue Photoluminescence and Excellent Stability. Adv. Funct. Mater. 2018, 28,1706446

(5) Xu, J.; Li, S.; Qin, C.; Feng, Z.; Du, Y. Identification of Singlet Self-Trapped Excitons in a New Family of White-Light-Emitting ZeroDimensional Compounds. J. Phys. Chem. C 2020, 124, 11625-11630. 